\title{
Study on Ecological Design of Agricultural Landscape in Northeast
}

\author{
China \\ Dong Chu ${ }^{1, a}$ \\ ${ }^{1}$ Harbin University of Commerce, Harbin, Heilongjiang, China \\ a110870893@qq.com
}

\begin{abstract}
Keywords: agricultural landscape, ecological design, imagery construction
Abstract: Agricultural landscape is a reality show about the agricultural civilization, which is an expression of the agricultural economy, society and other aspects, including cultivated land, crops, roads, canals and forest belts as the mosaics of the landscape patches. It is a kind of synthetic expression of the productivity and villages' culture. Based on the theory of landscape ecology, landscape aesthetics, landscape morphology and landscape architecture,the thesis discusses about the possibility of transforming the agricultural planting situation into design language after a deep study about the agricultural civilization, ice and snow culture, local folk culture.
\end{abstract}

\section{Introduction}

Agricultural landscape is a reality show about the agricultural civilization, which is an expression of the agricultural economy, society and other aspects, including cultivated land, crops, roads, canals and forest belts as the mosaics of the landscape patches. It is a kind of synthetic expression of the productivity and villages' culture. Based on the theory of landscape ecology, landscape aesthetics, landscape morphology and landscape architecture,the thesis discusses about the possibility of transforming the agricultural planting situation into design language after a deep study about the agricultural civilization, ice and snow culture, local folk culture. The result of the study could make up the history dividing of agricultural landscape and influence the design formation of the northeast agricultural landscape, which also gives some advice about the development of the tourist landscape. After putting forward the concept of the three-dimentional agricultural landscape, the scientific planning of urban agricultural landscape can be derived in order to meet the future demands of the ecological and supply demands in the future urban development. The ultimate goal is to protect the traditional landscape style in the countryside. The internal organizational principles should be spread to impact the landscape construction with different crops in different area. What the design method could do is to achieve coordinated urban and rural development, and improve the human settlement environment.

\section{First, Theoretical Value: The extension of Chinese farming culture}

As one of the oldest ancient agricultural country, farming is the basis for survival in China. The rural scenery had become the dream land for living for the scholars for a long time. The scholars spoke highly about the beauty of the rural scenery in the background of the agricultural society. No matter what the Book of Songs talked about the labor scene or the village landscape Tao Yuanming built for himself in the poem and the beautiful landscape in the painting of Wang Wei, Chinese garden design expresses a yearning for the nature of agriculture. In the poem of Jingu Garden written by Shi Chong said that there are springs, bamboos, herbs and forest in the garden with four aces of farm land and different poultry. It also designed with the rice-polishing device using water 
power, fish pool and soil cave for entertainment. Distinguished from European nomadic culture, China is famous for her agricultural civilization.People and land relations have continued up to now influenced by the agricultural civilization.

\section{Secondly, Practical Application Value}

Construction of agricultural culture, national culture and ice culture. The agricultural landscape includes not only natural landscapes and planting landscapes, but also contains other human landscapes, such as folk customs, religious beliefs, daily life. As the primary industry of agriculture, the traditional rural society is changing into the modern urban society in the process of urbanization. Because of the one-sided pursuit of modernization, the traditional production and living landscape disappeared.What we call the human landscape is not only the protection of physical form, but also the cultivation of beautiful land. The humanities landscape should also be inherited influenced be the local folk custom and social structure.

Landscape is the identity card of a nation,the rural landscape in Northeast China represents the externalization of regional cultural characteristics, which causes us facing to an identity crisis. The rural landscape, symbolizing regional culture, has been assimilated. The unified visual form limits people's spiritual freedom. The land is losing the spirituality and the cultural diversity. As a multicultural circle, there are many minorities living in the northeast, such as Manchu, Mongolian, South Korean, Oroqen, Ewenki and so on.Every nation has its own ideal environment pattern which is closely related to the culture of its own. Interpretation of these ethnic cultures which is applied to landscape design practice appropriately will create a landscape pattern consistent with regional cultural traditions.After following the heritage of regional culture as the new starting point, it will be carried out in a specific space layout, form and environment design. Furthermore, ice and snow culture as a common feature of Northeast China,should be skillfully translated in the practice of agricultural landscape design.

Ecological construction under the background of modernization. With the rapid development of industrialization, urbanization and agricultural modernization, the rural ecological environment is deteriorating day by day. Excessive use of chemical fertilizers and pesticides has brought harm to the quality of the land and caused food safety problems. Unilateral emphasis on productive agricultural landscape has been unable to adapt to the post-modern context of ecological design principles. The agricultural landscape has developed into a systematic category of integrated production, ecology, life. People have increasingly realized of the unsustainable nature of this design pattern. The ecological planning of agricultural landscape should not only focus on land use, as well as short-term productive demand, but also emphasize the long-term ecological and aesthetic value of landscape as a complex life.Based on the principle of landscape ecology, quantitative analysis of geospatial data can be got from the GIS. A variety of spatial and dynamic geospatial information can be provided, which could also build a scientific basis for landscape designers with its powerful spatial analysis function.

Economic value construction of agricultural landscape tourism. With the improvement of modern living standard, people are more and more eager to go back to rural tourism. Return to the original ecology is actually the Chinese attachment to farming culture. In the process of agricultural landscape planning in Northeast China, we can increase the opening area by dividing the regional patches. The deep experience of agricultural landscape tourism should be organized in order to supply the economic benefits of planting. Meanwhile the connection between farming culture and traditional festivals will play an important role in the process of design the local characteristics.

Imagery construction of urban agricultural landscape. The Western contemporary landscape 
architecture brings the country into the city, and reproduces the rural landscape in an artistic way. They learn from the seasonal changes of plants and then reappear natural scenery by the inspiration. The sustainable development of ecological environment can be realized by he stereoscopic construction of urban agricultural landscape. At the same time, the lack of Chinese food production and food safety which caused by the farmers who abandoned the farmland can be solved.

\section{Thirdly, Design Practice}

Project overview. The Golden Turtle Villa locates in Qing'an, Bayan, Beilin District's Golden Triangle area. It is 33 kilometers away from Suihua city and covers an area of 1 million square meters. The countryside is beautiful, where the natural resources are rich and unique in topography. However, the shortcomings of ecological planning and the lack of human landscape have failed to interpret the regional culture in Northeast China.The cultivated land, forest land and water environment are rich in the park, but the function of landscape planning is unitary and the recreation function is limited.

Project orientation. Rich agricultural ecological tourism zone Villa Planning Relying on the good ecological environment and rich agricultural resources, the Golden Turtle Villa design tries to build a Eco-tourism area through the organic combination of local mountains, water and fields. What important is the combination of agriculture, ecology, culture and tourism. Based on the interior landscape planning facilities of Golden Turtle Villa,the ecological design concept of the large-scale agriculture will be built relying on agricultural production.

Planning principles. The project planning follows the principle of "resource based, market oriented, design combined with nature", combining agriculture and tourism closely. Construct the functional system of industry, tourism and culture through the application of traditional agricultural experience and modern agricultural technology.It embodies the characteristics of whole, cycle, coordination and regeneration and realize the construction of agricultural landscape and folk culture image.

Ecological principle. Guided by the principles of ecology, the project carries out the layout of the landscape, integrating farming activities, natural scenery, science and technology demonstration, leisure and entertainment, environmental protection together. Make full use of the symbiosis of many organisms and link the ecological elements in the form of food chain, a virtuous cycle of ecological agricultural system is being established.

Productive principle. The agricultural demonstration area is based on the Agricultural experience design. The introduction of the intelligent agricultural system and the eco shopping experience model will improve the experience of the customers. The economic benefits of the park will be realized by the large-scale agricultural production and picking experience and farming activities.Agricultural tourism can not only increase the value of agricultural products, agricultural landscapes and agricultural civilization, but also increase the income of farmers.

Educative principle. The principles of knowledge, science and technology are the first rule to follow in the process of design. The introduction of the history about agriculture and the development of agriculture,could popularize the knowledge of agriculture and strengthen the education of environmental protection. On the one hand, it can provide the base for Science Education in local for the colleges and universities. On the other hand, it could provide a place for various exhibitions and large agricultural technical exchanges, academic conferences and agricultural training sites. 


\section{Conclusions}

The project was designed to encourage the implementation of the agricultural tradition, which promote activities linked to the countryside in order to reshape the relationship between agriculture and the city life. After the short-range design, it focuses on building an agricultural tourism project suitable for the local blocks. It will promote the development of regional low carbon urban agriculture town with the concept of large-scale agriculture.

As a man-made landscape, agriculture is a new type of landscape system. It could also provides a shared space, which is a spiritual retreat from the city. This is a man-made regular landscape, where farming is a living agricultural civilization. Only through the promotion of national cultural recognition and the improvement of the relationship between man and nature, can we improve the prospect of agricultural landscape development.

\section{Acknowledgment}

This work was financially supported by the Humanities and Social Sciences project of the Ministry of Education(15YJC760015), Innovative talent training program of the Education Department in Hei Longjiang Province(UNPYSCT-2016056), Arts and Science Program in Hei Longjiang province(2016D032) and Doctoral Research Project in Harbin University of Commerce(92508143), Youth Innovative Talent Support Program of Harbin University of Commerce(2016QN035).

\section{References}

[1] Viljoen, André , Bohn, Katrin, Howe, J. (Joe), in: Continuous Productive Urban Landscapes, edtied by China Building Industry Press(2015)

[2] Stephen K. Hamilton, Julie E. Doll, G. Philip Robertson, in: The Ecology of Agricultural Landscapes: Long-Term Research on the Path to Sustainability, edited by OUP USA (2015)

[3] John L. Motloch, in: Introduction to landscape design, edtied by John Wiley \&Sons (ASTA) Pte.Ltd(2000), in press.

[4] Jay Appleton, in: The Experience of Landscape, edtied by John Wiley \& Sons, Revised edition, (1996), in press.

[5] Richard G. Tansey, Fred S, Kleiner, in: Garden's Art Through the Age, vol II, edtied by Harcourt Brace College Publishers, New York(1996), in press.

[6] Viljoen, André , Bohn, Katrin, in:Second Nature Urban Agriculture, edtied by Routledge(2014)

[7] Monica G. Turner \& Robert H. Gardner \& Robert V. O'Neill, in: Landscape Ecology in theory and practice: Pattern and Process, edited by Springer-Verlag New York Inc.(2001), in press. 